Plant Tissue Cult. \& Biotech. 31(1): 81-95, 2021 (June)

(C)Bangladesh Assoc. for Plant Tissue Culture \& Biotechnology

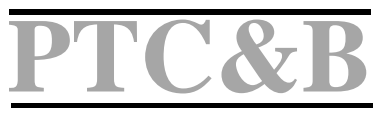

\title{
Assessment of Genetic Stability of Micropropagated Bambusa balcooa Roxb. using RAPD Marker
}

\author{
Meena Maiya Suwal, Janardan Lamichhane and Dhurva Prasad Gauchan* \\ Department of Biotechnology, School of Science, Kathmandu University, P.O. Box 6250, \\ Dhilikhel-45210, Kavrepalanchok, Dhulikhel, Nepal
}

Key words: Bamboo, BAP, clonal propagation, genetic fidelity, NAA, PCR-based marker

\begin{abstract}
Bambusa balcooa Roxb. was in vitro propagated by optimizing protocol using nodal segment from secondary branches with $100 \%$ success in MS liquid media containing 100 mg A Myo-inositol, 3\% sucrose supplement with $4.4-26.64 \mu \mathrm{M}$ BAP for shoot multiplication, and $2.69-32.26 \mu \mathrm{M}$ NAA for root induction. The highest shoot multiplication (14.53 \pm 0.33 folds), shoot length $(5.9 \pm 0.6 \mathrm{~cm})$, shoot number per explants $(4.0 \pm 0.24)$, and rooting $(89.3 \pm 0.33 \%)$ was obtained in MS liquid media supplement with 13.32 $\mu \mathrm{M}$ BAP (shooting) and $26.88 \mu \mathrm{M}$ NAA (rooting) and $1 \%$ aqueous leaf extract of Artemisia vulgaris L. (EAV). Twenty RAPD (Random amplified Polymorphic DNA) primers were used individually to amplify DNA of tissue culture-raised plants and the mother plant where 8 primers yielded monomorphic banding patterns with reproducible, clear, scorable bands (2.8 per primer) ranging from 250 to $1800 \mathrm{bp}$ respectively which revealed the micropropagated plants of $B$. balcooa retained their genetic stability.
\end{abstract}

\section{Introduction}

The current research trends and versatile application of the bamboo plant are most interesting and increased in the world due to its fast-growing nature, multipurpose use, evergreen plant, and economical potentiality. However, the chemical constitution of bamboos as crucial raw materials to the pharmaceuticals and pharmacological industries is vividly mentioned by different research (Re et al. 1999, Muniappan and Sundararaj 2003, Jun 2015, Wroblewska Katarzyna et al. 2019). Indeed it is traditionally practiced in ancient medicine in Asia (Sukla et al. 2012, Mandy 2015). It has the brightest prospect. People often consider bamboo as a symbol of good luck charm, and love (Piper 1992).

*Author for correspondence: <gauchan@ku.edu.np>.

DOI: https://doi.org/10.3329/ptcb.v31i1.54114 
The Korean people assumed that bamboo is symbolic of gentleman and person of novel virtue (Son and Yun 2014). Similarly, it is known as "poor's man timber", in India, indeed, it is prioritized as an important element for the eradication of poverty, economic, environmental development, and a basic livelihood crop and material for rural people living in Asia, Africa, and Latin America (Oliver 1956).

The genus, Bambusa balcooa Roxb., is one of the strongest and tallest bamboo, belonging to the family Poaceae under subfamily Bambusoideae are widely distributed in tropical to the subtropical region of Asian countries including Nepal (Stapleton 1994, Bystriakovaet al. 2003). It is commonly known as tropical clumping female bamboo. It is perennial, densely tufted, and sympodial bamboo and locally known as "Haroth" in the Tarai region and "Dhanu bans" in the hilly region of Nepal. It is distributed in Tarai to the hilly region of Nepal in the range of $100 \mathrm{~m}$ to $1500 \mathrm{~m}$ from sea level (Stapleton 1994). It is found in any type of moist soil having alkaline with a $\mathrm{pH}$ range from 5.5 to 8.5. The unique physical characteristics and fast growth rate of bamboo (B. balcooa) are considered as effective to sequester the carbon content of the environment which is essential to play a role in the mitigation of global climate change (Lobovikov et al. 2009). Living bamboo can significantly store 200 to 400 tonnes of carbon per hectare while tree plantations (Teak, Shorea, etc.) store between 90 to 420 tonnes (Vander Lugt et al. 2018). Bamboo products may be included in future greenhouse gas reduction protocols including plastic pollution where it is used frequently.

The network system of root structure has the potential anchorage to soil strongly so it is an alternative resource for the conservation of soil erosion and stability of land pattern (Banik 1995). B. balcooa is one of the most important bamboos which has been widely used for construction, paper making, fishing materials, agricultural utensil, furniture, household's accessories in Nepal. Also, it has played a very significant role to make pens for writing, spoons, parts of digital applicants, charcoal, sheer materials, etc. It has a great role in the economic development of low cast people such as Dum, Pahadi, Ram, Mushahar, etc. along with villagers (Das and Thapa 2013). The young shoots are consumed as food in the form of vegetables and pickles. The leaf extract of B. balcooa has the potential to make medicine for antiulcer (Upreti et al. 2016). The products of B. balcooa are eco-friendly and non-hazardous plant materials so the products of bamboos are highly demanding in the market however there is insufficient plant resource available which is difficult to fulfill the demand. Hence, the range of deforestation and depletion of natural resources continues to increase at an alarming rate. Deforestation leads to land degradation as well as the loss of germplasm of B. balcooa. Moreover, this species is monocarpic living for many years (55 to 60 years) before flowering, and seeding gregariously for 1-3 years before dying (Tewari 1992). Therefore, conventionally, it is regeneration through vegetative propagation such as rhizome, culm cutting, offsets, and branch cutting. But, this technique is a slow process and low rooting frequency which has been reported by (Pattanaik et al. 2004)(66.7\%) and Sheethalaxmi (Seethalakshmi et al. 1983) $(40 \%)$ in rooting hormone treatments. Hence, the vegetative propagation methods 
can not supplement the necessity of the demanding bamboo (Vishwanath et al. 2012). In the vegetative propagation technique, there is the destruction of a huge mass of mother plant stocks which not only difficult to transport and handle (Gielis et al. 2002, Singh et al. 2013) in fact, the huge mass of plant stock used means it tends to the destruction of an ecological clock as well as it tends to lose the germplasm of $B$. balcooa. The alternative technique, micropropagation promise to regenerate the mass of plants from a single nodal segment explant in vitro propagation (Gielis et al. 2002). Therefore, the development of an efficient propagation protocol is essential for protecting natural resources, helping to accomplish the increasing demand and eventually conservation of germplasm for B. balcooa.

Micropropagation on $B$. balcooa has been reported by many groups in different countries (Das and Pal 2005a, Das and Pal 2005b, Islam and Rahman 2005, Mudoi and Borthakur 2009, Negi and Saxena 2011, Choudhary et al. 2017, Gantait et al. 2018, Thapa et al. 2018) however, there is lack of efficient protocol for mass propagation due to obstacle on the establishment of culture, low rate of rooting, the uncertainty of genetic stability.

Despite many advantages of micropropagation technique, somaclonal variation has occurred among the tissue culture raised plants due to various factors like DNA methylation or chromosomal mutations, and gene mutation or chemical treatment for inoculation to explant or exogenously applied plant growth regulators (PGR) and prolong exposed in PGR (Peschke and Philipss 1992, Leory et al. 2000, Venkatachalam et al. 2007) or continuously shoot proliferation. Hence, it is extremely important to ascertain the genetic stability of tissue culture-raised plants (Agnihotri et al. 2009, Singh et al. 2013b) by applying more efficient detection tools like molecular markers. Molecular markers are reliable indicators of genetic diversity which is used to monitor DNA sequence variation in intra-species and inter-species due to the revelation of differences at the whole genome level. Among the various molecular markers to analyze the genetic diversity and genetic stability, PCR-based markers, such as ISSR (Zietkiewiez et al. 1994) and RAPD (Raina et al. 2001) are the most popular applications because it doesn't need any specified sequences (Raina et al. 2001). ISSR and RAPD markers are emerging as simple, fast, reliable, reproducible, and low-cost tools for assessing the genetic stability of tissue cultured raised plants that are not influenced by age, growth condition, and environment. The present study aimed to optimize a protocol for large-scale propagation of B.balcooa and to evaluate the genetic fidelity of tissue culture-raised plants using a molecular marker (RAPD).

\section{Material and Methods}

The single nodal segments used as explants for mass propagation of B. balcooa, were collected from the Saptari district of $\left(26^{\circ} 39.477^{\prime} \mathrm{N}, 085^{\circ} 30.481^{\prime} \mathrm{E}\right)$ Nepal. The collected samples were wrapped with a moist paper towel, and stored in an airtight zipper-lock 
bag. The micropropagation was performed at the plant tissue culture Laboratory of the Department of Biotechnology, School of Science, Kathmandu University, Dhulikhel, Kavre, Nepal. The present study was conducted using the full strength of MS medium in liquid culture supplemented with 6-benzylamino purine (BAP), and naphthaleneacetic acid (NAA). The media was further supplemented with an aqueous leaf extract of Artemisia vulgaris L. (EAV) to control the contamination (Halina et al. 2020). The $\mathrm{pH}$ of all media was adjusted to 5.8 with the addition of either $0.1 \mathrm{~N} \mathrm{NaOH}$ or $\mathrm{HCl}$ and autoclaved at $121^{\circ} \mathrm{C}$ under $15 \mathrm{lbs}$ pressure for 20 minutes. The immature fresh leaves of Artimisia vulagaris L. were collected from the premises of Kathmandu University and washed thoroughly with tap water and left for air drying. The dried leaves were grounded into a fine powder and soaked into distilled water in a ratio of 1:4 proportion for 72 hours. The extract was filtered through Whatman No. 1 filter paper and centrifuged at $1000 \mathrm{rpm}$. The supernatant was collected and again filtered by a $0.22 \mu \mathrm{M}$ size syringe filter and stored at $4^{\circ} \mathrm{C}$ for further use.

The single nodal segments were treated with $70 \%$ ethanol for 1 minute and then left under running tap water for 1 hour with1-3 drops of Tween-20. Then samples were further treated with $2 \%$ Bavistine (Fungicide) for 15 minutes and followed surfacesterilized in $0.1 \%$ Mercuric chloride solution for 15 minutes and finally rines with sterilized distilled water 4 to 5 times. The explants were inoculated in MS liquid media on a serrate filter bridge in treatments of $2.2 \mu \mathrm{M}$ to $26.4 \mu \mathrm{M} 6 \mathrm{BAP}$ separately and the control condition was MS liquid media only.6 to 8 numbers of propagules were transferred into new fresh shoot multiplication media supplemented of $4.4 \mu \mathrm{M}$ to 26.4 $\mu \mathrm{M}$ BAP and 0.5 to $2.5 \%$, additives, an aqueous extract of EAV for the proliferation of shoots. 8 to 10 numbers of shoots were transferred to MS liquid media the supplement with auxin,5.37-32.22 $\mu \mathrm{M}$ NAA and 1\% EAV. The cultured bottles were transferred to the growth culture room under fluorescent white light with a dark light cycle of $8 / 16$ at light intensity $50 \mu \mathrm{mol} \mathrm{m} \mathrm{m}^{-2} / \mathrm{s}$ at $25 \pm 2^{\circ} \mathrm{C}$. The experiments were performed triplicated for each treatment in 10 different culture bottles. After 35 days of root initiation, the regenerated in vitro plants were transferred to the sterile sand to provide optimal anchorage to the saplings for a week in the screen house retaining relative humidity (70$85 \%$ ). The acclimatized plants were transferred to the different compositions of the potting mixture containing soil, sand, and vermicompost in the ratio of $1: 1: 1,2: 1: 1$, and $1: 1: 2(\mathrm{v} / \mathrm{N})$ and soil, sand, and ashes of straw in the ratio of $1: 1: 1,2: 1: 1$ and 1:1:2 $(v / v)$. Each experiment was performed in triplicate for each treatment.

The isolation of DNA from mother plants and tissue culture-raised plants was performed using CTAB (hexadecyltrimethylammonium bromide) extraction protocol described by Doyle (1991) with some modification. For polymorphic Chain Reaction (PCR), a total of 20 OPA RAPD markers (Sigma-Aldrich, Banglore, India) were used and among them, only eight RAPD markers with clear and reproducible bands were considered for the analysis. The PCR amplification was performed on a final volume of $25 \mu \mathrm{l}$ containing $8.2 \mu \mathrm{l}$ sterile water, $2.5 \mu \mathrm{l}$ genomic DNA, $2.0 \mu \mathrm{L}$ each primer, $12.5 \mu \mathrm{L}$ 
Mater mix, and $0.3 \mu 1$ Taq polymerase. The PCR amplification was carried out in PCR machine (BIO-RAD, T100* Thermal cycler, World Friends) programmed at $94^{\circ} \mathrm{C}$ for 4 minutes of initiation of denaturation followed by 44 cycles of denaturation at $94^{\circ} \mathrm{C}$ for 1 minute, the annealing at $37^{\circ} \mathrm{C}$ for 1 minute followed by primer extension at $72^{\circ} \mathrm{C}$ for 2 minutes, and the final extension at $72^{\circ} \mathrm{C}$ for 10 minutes. For testing primer amplification, PCR products were detected on $2 \%$ agarose gel with a constant voltage of $90 \mathrm{~V}$ for 60 minutes. The amplification of PCR products using RAPD markers was determined by the comparison with a $1 \mathrm{~kb}$ DNA ladder marker (Takra, USA). The reproducible, consistently produced, and well-resolved fragments obtained through amplification by RAPD markers were considered and scored manually. The scoring bands were manually counted based on their presence (1) or absence (0) in the gel, and the Polymorphic information content (PIC) was calculated using the formula (Liu 1998).

$$
\mathrm{PIC}_{\mathrm{j}}=1-\sum_{\mathrm{i}=1}^{\mathrm{n}} \mathrm{P}^{2} \mathrm{i}
$$

Where $i$ is the ith allele of the jth marker, $n$ is the number of the jth marker's alleles. $P$ is allele frequency. The micropropagation of B.balcooa data was recorded separately such as bud initiation, shoot, and root induction in triplicate and statistically analyzed for significance using one-way ANOVA, and the differences were analyzed by DMRT at $\mathrm{p} \leq$ 0.05 using SPSS version 20. The results were represented as Mean \pm SE of means of experiments.

\section{Results and Discussion}

The earliest bud initiation occurred from the nodal segments (branches) of B. balcooa Roxb. was observed in MS liquid media within 4 days of culture. The highest bud break $(99.66 \pm 0.33 \%)$ occurred in MS liquid media fortified with $4.44 \mu \mathrm{M} / \mathrm{LAP}$ (Fig. 1) while Negi and Saxena (Negi and Saxena 2011) have succeeded only $90 \%$ bud break in MS liquid media with the supplement of BAP and $\mathrm{KN}$ in combined. Unlike, Das and Pal (Das and Pal 2005a) obtained 50\% bud break and 70\% bud break was reported by Mudoi and Borthakur (Mudoi and Borthakur 2009). Again, Choudhary et al. (2017) reported an 80\% bud break in BAP alone used in MS semi-solid media. Different frequencies of bud break occurred in MS liquid media supplement with BAP in different concentrations as 8.88 $\mu \mathrm{M}(78.66 \pm 0.6 \%), 13.32 \mu \mathrm{M}(66 \pm 0.57 \%), 17.76 \mu \mathrm{M}(55.33 \pm 0.3 \%), 22.2 \mu \mathrm{M}(43.33 \pm$ $0.33 \%)$, and $26.64 \mu \mathrm{M}(0.26 \pm 0.3 \%)$, respectively (Fig. 1) while in MS liquid media without growth regulators, the bud sprouting (bud break) was $45.33 \pm 0.3 \%$ (Fig. 1). According to Mishra et al. (2008), in B. tulda, Rathore et al. (2005) in Pseudoxytenathera stocksii, Ramanayake and Yakandawala (1997), in Dendrocalamus giganteus, Mudoi and Borthakur (2009) and Negi and Saxena(2011), in B.balcooa, the frequency of bud break was influenced by the seasons and rainfall. In our study, the seasonal variation and rainfall did not influence the frequency of bud break in vitro culture. Similarly, $85 \%$ bud break was reported by Choudhary et al.(2017) in MS solid media with the supplement of 
$2 \mathrm{mg} / \mathrm{BAP}$ and $0.5 \mathrm{mg} / \mathrm{Kn}$ while Thapa et al. (2018) achieved a 75\% bud break in the MS semi-solid media with a supplement of $3 \mathrm{mg} /$ BAP in B.balcooa. Despite, the bud break occurred within 10 days of inoculation in all treatments, the frequency of the bud initiation varied with different treatments. In our study, the shoot proliferation was highest (11.26 \pm 0.88 folds) in the shooting media fortified with $13.32 \mu \mathrm{M}$ BAP whereas in MS media shoot multiplication fold was obtained $1.3 \pm 0.57$ (Fig. 1).

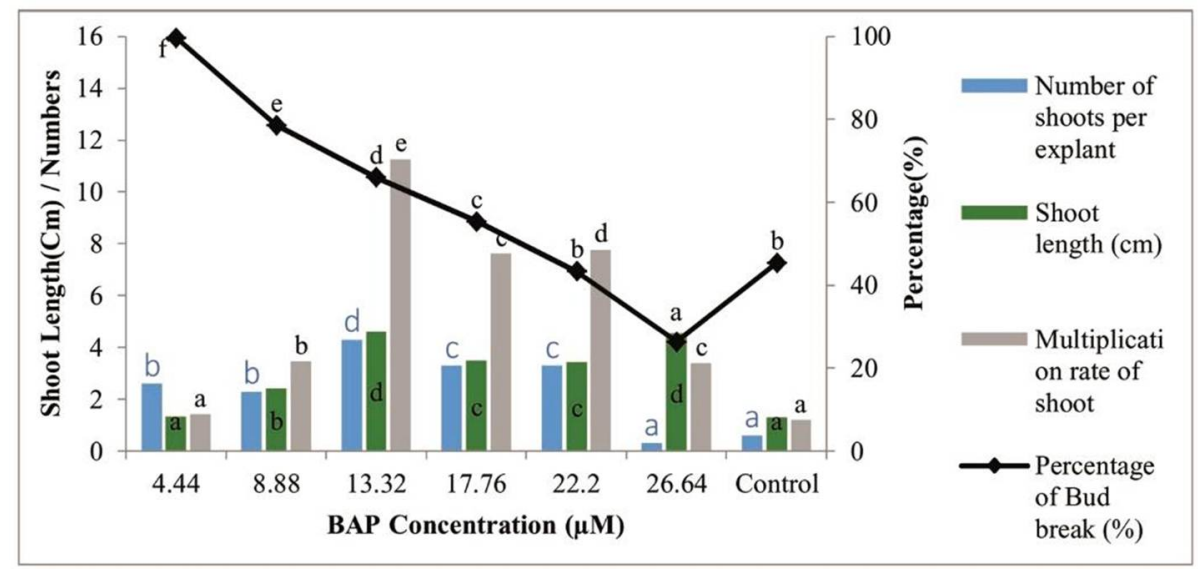

Fig. 1. Effect of different concentrations of BAP in bud break, number of shoot initiation, and multiplication of shoots in vitro culture of B. balcooa. Data represent in Mean \pm SE. Mean values with the different letters are significant at $\mathrm{p} \leq 0.05$ by the DMRT.

Meat, malt, yeast extract, juices, pulp, and fruit extracts like tomatoes and bananas, extracts of seedlings and plant leaves, plant sap, and protein hydrolysate have been widely used to enhance the growth and development of in vitro plants (George et al. 2008, Moltan et al. 2011). In the present study, we used aqueous leaf extract of Artimisia vulgaris L. to control the contamination of the in vitro culture and evaluate the effect of the additives in the shoot multiplication, and development and growth of plants. The genus A. vulagaris belongs to the Asteraceae family rich in essential oil, flavonoids, phenolic acid, and bitter substances, vitamins, coumarin. Recently researchers claimed that this species exhibits antibacterial, antifungal, antioxidant, hypolipidemic, hepatoprotective, antispasmolytic, analgesic, estrogenic, cytotoxic (Blagojevic et al. 2006, Singh et al. 2011, Baykan et al. 2012, Halina et al. 2020). In our study, the contamination of the culture was fully controlled in addition to $1 \%$ EAV to the MS liquid media with the supplement of $4.44 \mu \mathrm{M} \wedge \mathrm{BAP}$ and also enhanced the length and number of shoots increment (Fig. 2, Fig. 4, A and B) However, the increasing concentration of EAV caused the depletion of the bud initiation, shoot multiplication and shoot numbers.

The 8 to 10 shoots transferred to the liquid media fortified with $23.25 \mu \mathrm{M}$ NAA gave the best result (maximum root percent, $89.3 \pm 0.33 \%$ ) for in vitro initiation of roots within 12 to 15 days of inoculation (Fig. 4, C and D). But, Negi and Saxena (2011) and Chaudhary et al. (2017) reported that the root initiation was observed in the half strength 


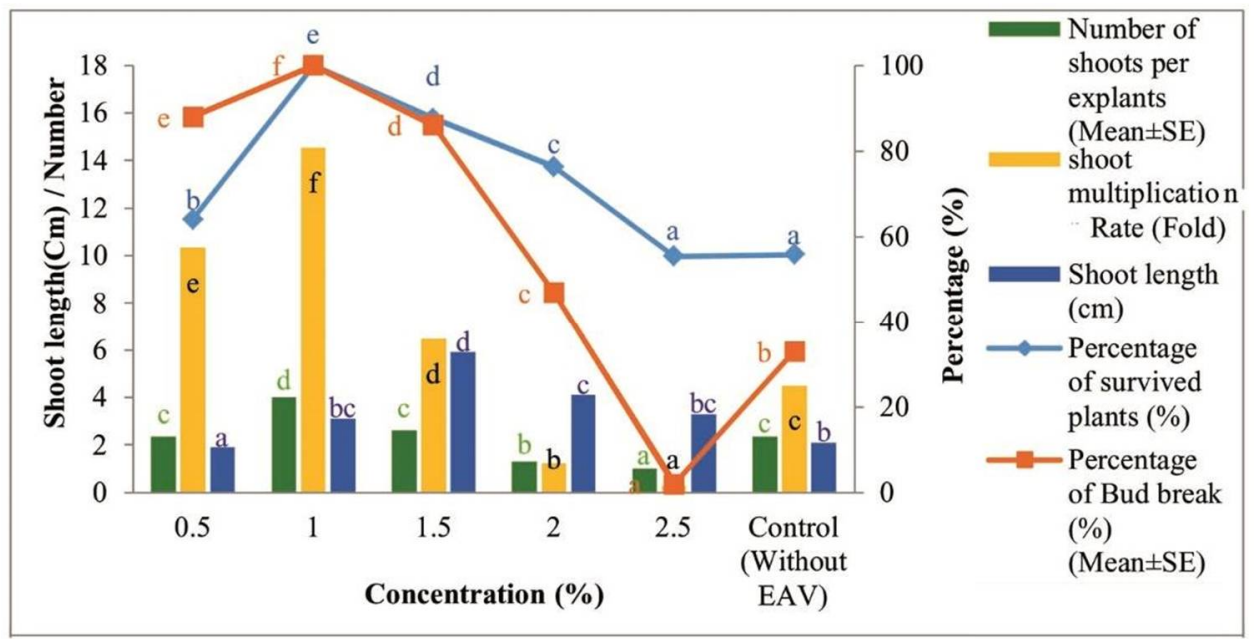

Fig. 2. Effects of aqueous leaf extract of Artemisia vulgaris (EAV) on bud break in MS liquid media fortified with $4.44 \mu \mathrm{M}$ BAP and shoot multiplication in MS liquid media supplemented with $13.32 \mu \mathrm{M}$ BAP on in vitro propagation of B. balcooa. Data represent Mean $\pm \mathrm{SE}$, each treatment tested 30 samples in triplicated experiments. Mean values with the same letter are not significant at $\mathrm{p} \leq 0.05$ on the DMRT.

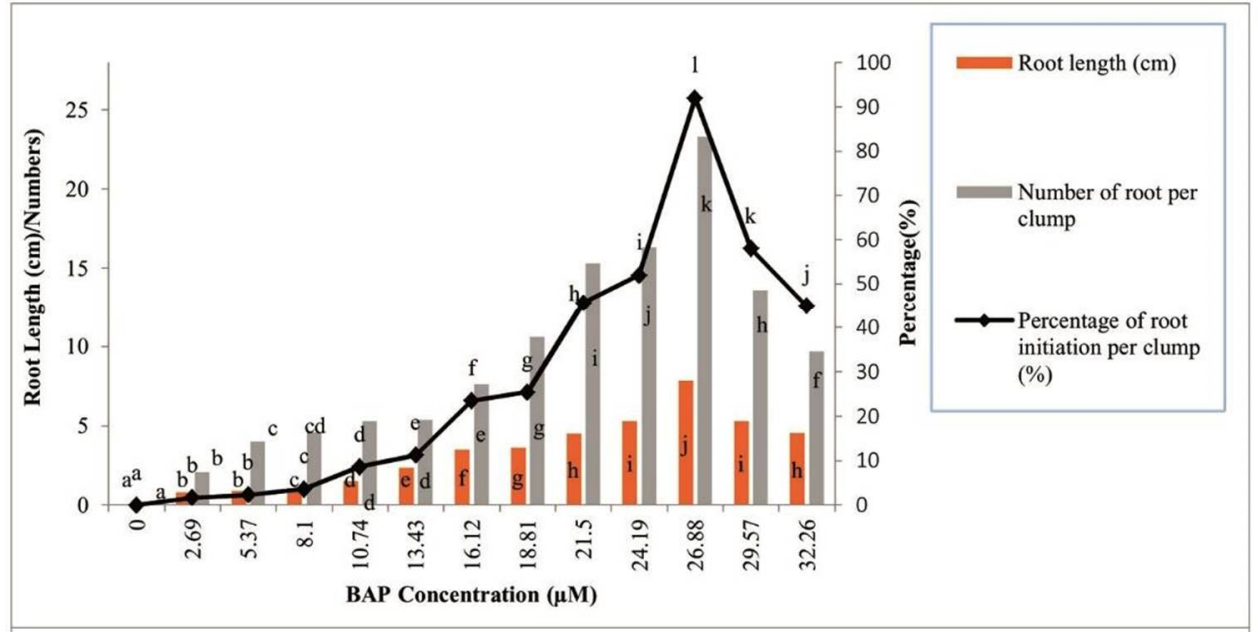

Fig. 3. Effects of different concentrations of NAA on in vitro rooting of B. balcooa Roxb. Data represent Mean \pm SE of 10 shoots per treatment in triplicated experiments. Mean values with the different letters are significant at $\mathrm{p} \leq 0.05$ based on one-way ANOVA followed by DMRT.

of MS solid media supplement with 2.5 to $5 \mathrm{mg} \Lambda$ NAA but they encountered the problem of dryness of clumps after root initiation. In contrast, we obtained maximum root number, $(23.3 \pm 0.3)$ per clump and root length $(7.86 \pm 0.33 \mathrm{~cm})$ (Fig. 3) in full strength liquid media supplement with NAA and $1 \%$ EAV without any obstacle in culture. On the 
other hand, in MS liquid media without supplement of rooting hormones and additives, the shoots were rootless with the proliferation of shoots (Fig.3). The rooted in vitro plantlets, after 35 days of root initiation were acclimatized in the sterilized sand which was secondary hardening to a polybag containing potting mixture with different ratios of various components of soil, sand, and vermicompost $(1: 1: 1,2: 1: 1,1: 1: 2, \mathrm{v} / \mathrm{N})$ and soil, sand, and ashes $(1: 1: 1,2: 1: 1,1: 1: 2, \mathrm{v} / \mathrm{v})$ respectively. A combination of soil, sand, and ashes in the ratio of 1:1:2 (v/N) were found 100\% hardening success (Fig. 4E) whereas the combination of soil, sand, and vermicompost in the ratio of $2: 1: 1,(\mathrm{v} / \mathrm{N})$ obtained $98 \%$ hardening success (Fig. 4E). The high nitrogen and minerals are deposited
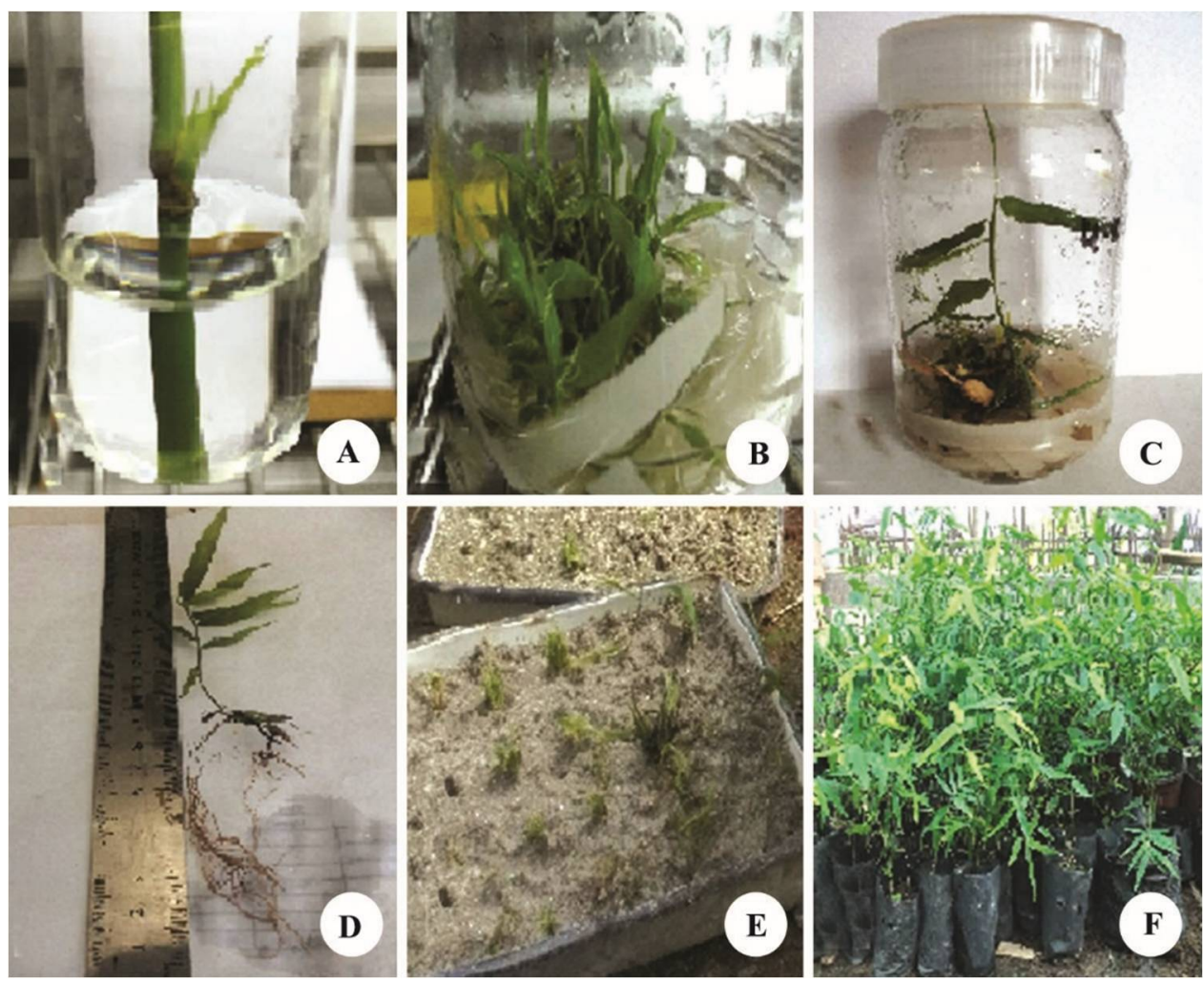

Fig. 4. In vitro propagation of Bambusa balcooa Roxb. in MS liquid media: A) Initiation of bud, B) Shoot multiplication, C) Rooting, D) Measurement of the root, E) Hardening of Tissue culture raised plants in sterilized sand, F) Hardening of plants in polybags with the potting mixture of sand, soil and ash $(1: 1: 2, v / v)$.

in the ashes can easily uptake by the plants which influence plant growth and development. Ash is an excellent source of lime, phosphorus, magnesium, calcium, and potassium and it provides many of the trace elements that plant need to thrive. Ashes contain 0.1-3 nitrogen, potassium, and phosphorus (Etiegni and Campbell 1991, Risse 
and Julia 2013). Singh et al. (2013) reported a high survivability rate in the combination of Dune sand and vermicompost for the hardening of $D$. hamiltonii. The potting mixture of soil, sand, cocopeat, vermicompost, and soil rite was tested by various researchers (Suwal et al. 2020). According to Mishra et al. (2011), soil rite was found most suitable for the hardening of B. tulda. However, the composition of Cow dung, sand, and soil was also suitable for the hardening of bamboo (Choudhary et al. 2017).

With the prolonged exposure of tissue culture-raised plants in plant growth hormones and due to the properties of plant growth hormones, there are possibilities to occur genetic variation. So, a somaclonal variation is a common event in the in vitro culture plants due to genetic modification, DNA methylation, chromosomal abbreviation, gene mutation, or external factors, that are reflected in the banding profiles developed by applying different markers (Joshi 2007). For the detection of genetic stability which is important to maintain the quality of tissue culture-raised plants, DNA-based molecular markers are used. RAPD marker is one of the effective tools to assess genetic homogeneity, stability because it is cost-effective, reproducible, and not influenced by the environment for bamboo plants (Das and Pal 2005a, Singh et al. 2013, Anand et al. 2013, Goyal et al. 2015, Annisa 2019). The isolated DNA was amplified only by 8 primers with cleared, unambiguous, consistent, reproducible, uniform, and scorable bands through Polymer Chain Reaction (PCR) out of 20 RAPD primers (Tables 1 and 2). The amplification with 8 number of RAPD primers has yielded 22.44 numbers of reproducible and cleared band scores with 2.8 bands per and band size ranging from 100 to 1800 bp (Table 2). The produced DNA amplification bands by RAPD markers were monomorphic across the tissue culture-raised plants and mother plants which confirmed the genetic homogeneity, true-to-type, and genetical stability (Fig. 5, G1-G4). The polymorphism information (PIC) was 0.2 with 0.4 per primers. The number of amplified bands ranges from 1 (OPA-10) to 3.66 (OPA-18). The RAPD primer namely OPA-2, OPA7, OPA-12, OPA-17,OPA-19 and OPA-20 amplified allele 3.25, 2.66, 1.6, 3.5, 3.33, and 3.5 respectively in the gel visualization (Table 2). The largest allele size was approximately $1800 \mathrm{bp}$ observed in OPA-7 (Fig. 5, G1) primer amplification and the smallest allele size approximately $250 \mathrm{bp}$ was amplified by OPA-20 Primer (Table 2). The allele size amplified by 8 RAPD primers was monomorphic from in vitro raised plants to each other and the allele size of its mother plants too. There was not observed intraclonal variation because a high degree of genetic homogeneity and monomorphism was present in regenerated $B$. balcooa plants and that help to confirming the genetic stability of the plants as the clonal fidelity among in vitro raised plants of bamboo. Similarly, Negi and Saxena (2010) have claimed that the tissue culture raised plants to have genetic fidelity to the mother plants of B. balcooa employing 15 ISSR markers. Mehta et al. (2011) also publicized that the genetic stability of $B$. nutans can be assessed by applying DNA-based markers (RAPD and ISSR). Another study in G. anguustifolia (Nadha et al. 2011) also confirmed that genetic uniformity can be established employing RAPD and ISSR markers. Singh 
Table 1. Screening of 20 RAPD primers for amplifying genomic DNA in B. balcooa mother plants and tissue culture raised plants by RAPD PCR technique.

\begin{tabular}{llll}
\hline Sl.No. & Name of Primer & Primer sequence (5'to 3') & DNA amplification \\
\hline 1 & OPA-01 & CAGGCCCTTC & Absent \\
2 & OPA-02 & TGCCGAGCTG & Cleared bands \\
3 & OPA-03 & AGTCAGCCAC & Absent \\
4 & OPA-04 & AATCGGGCTG & Absent \\
5 & OPA-05 & AGGGGTCTTG & Absent \\
6 & OPA-06 & GGTCCCTGAC & Absent \\
7 & OPA-07 & GAAACGGGTG & Cleared bands \\
8 & OPA-08 & GTGACGTAGG & Absent \\
9 & OPA-09 & GGGTAACGCC & Absent \\
10 & OPA-10 & GTGATCGCAG & Cleared bands \\
11 & OPA-11 & CAATCGCCGT & Absent \\
12 & OPA-12 & TCGGCGATAG & Cleared bands \\
13 & OPA-13 & CAGCACCCAC & Absent \\
14 & OPA-14 & TGTGTGCTGG & Absent \\
15 & OPA-15 & TTCCGAACCC & Absent \\
16 & OPA-16 & AGCCAGCGAA & Absent \\
17 & OPA-17 & GACCGCTTGT & Cleared bands \\
18 & OPA-18 & AGGTGACCGT & Cleared bands \\
19 & OPA-19 & CAAACGTCGG & Cleared bands \\
20 & OPA-20 & GTTGCGATCC & Cleared bands \\
\hline
\end{tabular}

Table 2. Number of visible distinct bands in the RAPD primers, monomorphism \%, Polymorphic Information Content (PIC) value, and size of the amplified fragments generated in the mother plants and the in vitro regenerated plants of B. balcooa.

\begin{tabular}{|c|c|c|c|c|c|}
\hline Sl.No. & $\begin{array}{l}\text { Name of Primer } \\
\text { used in RAPD- } \\
\text { PCR }\end{array}$ & $\begin{array}{l}\text { Total scorable } \\
\text { bands }\end{array}$ & $\begin{array}{l}\text { Monomorphism } \\
(\%)\end{array}$ & PIC values & $\begin{array}{l}\text { Amplified size } \\
\text { range } \\
\text { [base pair, }(b p)]\end{array}$ \\
\hline 1 & OPA-2 & 3.25 & 100 & 0.33 & $500-750$ \\
\hline 2 & OPA7 & 2.66 & 100 & 0.4 & $500-1800$ \\
\hline 3 & OPA-10 & 1 & 100 & 0.0 & $500-1500$ \\
\hline 4 & OPA-12 & 1.6 & 100 & 0.0 & $500-850$ \\
\hline 5 & OPA-17 & 3.5 & 100 & 0.25 & $250-750$ \\
\hline 6 & OPA18 & 3.66 & 100 & 0.15 & $500-1600$ \\
\hline 7 & OPA-19 & 3.33 & 100 & 0.25 & $500-1000$ \\
\hline \multirow[t]{2}{*}{8} & OPA-20 & 3.5 & 100 & 0.22 & $250-750$ \\
\hline & Average & 2.8 & & 0.2 & \\
\hline
\end{tabular}

et al. (2013), applied RAPD, ISSR, AFLP, SSR markers to study the genetic fidelity of $D$. hamiltonii and D. asper. Goyal et al. (2015) used 10 RAPD and 9 ISSR markers to assess the genetic stability of $D$. stricus. Both RAPD and ISSR markers help in detecting 
polymorphism. Both RAPD and ISSR markers give the same score bands in gel run. Again, RAPD markers are considered to be uniformly distributed along the genome and randomly amplified whereas ISSR is found only between microsatellite loci. Das and Pal (2005a) have reported the establishment of
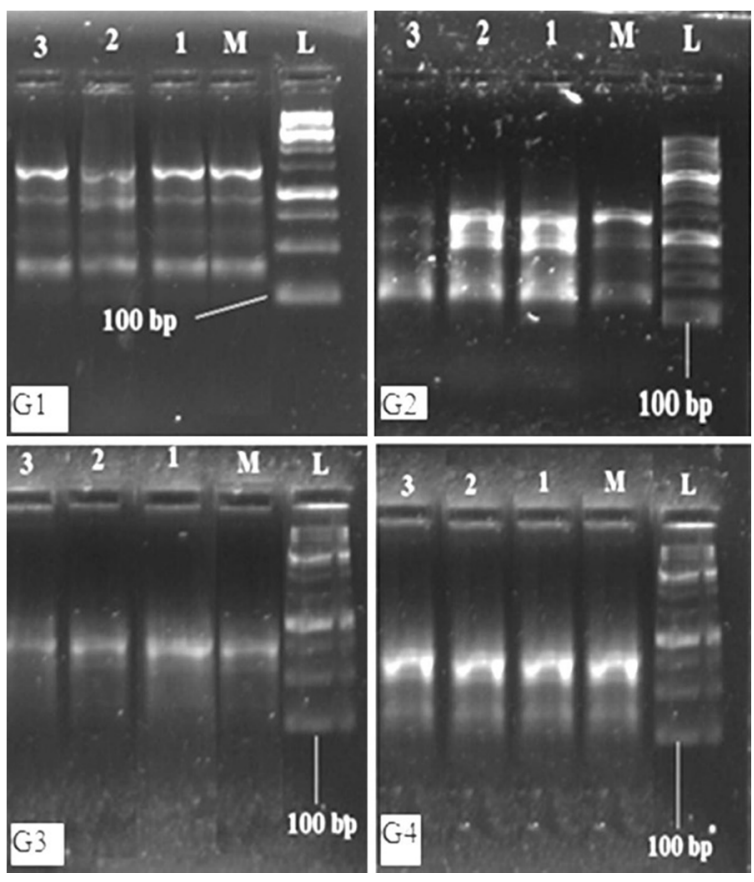

Fig. 5. Genetic stability assessment of tissue culture raised plants of B. balcooa Roxb. using RAPD markers. G1, G2, G3, and G4 are banding patterns of RAPD-PCR products using primers of OPA-7, OPA 18, OPA-10, and OPA-12, respectively in $1.5 \%$ gel, Lane $\mathrm{L}=1 \mathrm{~kb}$ Ladder marker, Lane $\mathrm{M}=$ Mother plant, Lane 1-3=Tissue culture raised plants propagated in MS liquid media supplement with $26.88 \mu \mathrm{M}$ NAA and $1 \%$ EAV.

clonal fidelity of micropropagated plants of B. tulda and B. balcooa by employing RAPDPCR. Hence, in the present study, RAPD markers were employed to evaluate the clonal stability of B. balcooa. This study revealed that the in vitro raised plants of B. balcooa had shown homogeneity and uniformity to the mother plants. There was no somaclonal variation occurred and the in vitro raised plants are true-to-type clones hence the optimized protocol help to provide for the production of mass plantlets without the destruction of the quality of the mother plant which improves the conservation of germplasm of B. balcooa.

\section{Acknowledgment}

The authors wish to thank the President Chure- TaraiMadesh Conservation Development Board to provide funds to conduct this work and we also thank the Department of 
Biotechnology, School of Science, Kathmandu University for providing the facility to perform this work.

\section{References}

Agnihotri RK and Nandi SK (2009) Improved in vitro shoot multiplication and rooting of Dendrocalamus hamiltonii Nees et Arn. ex Munro: production of genetically uniform plants and field evaluation. Acta Physiol Plant. 31: 961-967.

Anand M, Brar J and Sood A (2013) In vitro Propagation of an Edible Bamboo Bambusa bamboosand Assessment of Clonal Fidelity through Molecular Markers. Journal of Medical and Bioengineering. 2(4): 257-261. doi:https://doi.org/10.12720 ßomb.2.4.257-261

Annisa, Hafzari R, Tia Setiawati, Budi Irawan and Joko Kusmoro (2019) Evaluation of RAPD markers for molecular identification of five bamboo genera from Indonesia. Folia Forestalia Polonica, Series A - Forestry. 61(4): 255-266. doi:10.2478/ffp-2019-0025.

Banik RL (1995) A manual for vegetative propagation of bamboos (Vol.1). Bangladesh Forest Research Institutes: International Development Research Center UNDP/FAO Regional Forest Tree Improvement Project. pp-89.

Baykan Erel, Reznicek S, Senol G, Karabay Yavaso `Gulu, and NÜ Konyalio `Glu S (2012) Antimicrobial and antioxidant properties of Artemisia L. species from western Anatolia. Turk. J. Biol. 36(2012): 75-84. doi:10.3906 biy-0912-27

Blagojevi'c P, Radulovi'c N, Pali'c R and Stojanovi'c G (2006) Chemical, composition of the essential oils of Serbian wild-growing Artemisia absinthium and Artemisia vulgaris. J. Agric. Food Chem. 54:4780-4789. doi: 10.1021 倓060123o.

Bystriakova N, Kapos V, Lysenko I and Stapleton CMA (2003) Distribution and conservation status of forest bamboo biodiversity in Asia- Pacific region. Biodiversity and conservation. 12(9):8. doi:https://doi.org/10.1023/A:1024139813651

Choudhary AK, Priyanka K and Ashish R (2017) Refinement of protocol for rapid clonal regeneration of economical bamboo, Bambusa balcooain the agroclimatic conditions of Bihar, India. African Journal of Biotechnology. 16(10): 450-462. doi:https://doi.org/10.5897/ AJB2016.15771

Das AN and Thapa HB (2013) Distribution and utilization of bamboos in the midwestern and the far-western regions of Nepal. Banko Janakari. 21(1):13-24. doi:https://doi.org/10.3126/ banko.v21i1.9059

Das M and Pal A (2005a) Clonal Propagation and Production of Genetically Uniform Regenerants from Axillary Meristems of Adult Bamboo. J. Plant Biochem. Biotechnol. 14:185-188. doi:https://doi.org/10.1007/BF03355956

Das M and Pal A (2005b) In vitro regeneration of Bambusa balcooa Roxb.: Factors affecting changes of morphogenetic competence in the axillary buds. Plant Cell Tiss Organ Cult. 81:109113. doi:10.1007/311240-004-3017-x.

Doyle J (1991) DNA Protocols for Plants (Vol. 57). Berlin, Heidelberg.: Springer.

Halina Ekiert, Joanna Pajor, Paweł Klin, Agnieszka Rzepiela, Halina 'Slesak and Agnieszka Szopa (2020) Significance of Artemisia vulgaris L. (Common Mugwort) in the History of Medicine and Its Possible Contemporary Applications Substantiated by Phytochemical and Pharmacological Studies. Molecules (MDPI). 25 (4415):1- 32. doi:10.3390/molecules25194415

Etiegni L and Campbell AG (1991) Physical and Chemical Characteristics of Wood Ash. Resource Technology. 37: 173-178. 
Gantait S, Pramanik Binay Ray, Banerjee Maitreyi (2018) Optimization of planting materials for large scale plantation of Bambusa balcooa Roxb.: Influence of propagation methods. doi:https://doi.org/10.1016/j.jssas.2015.11.008

George EF Hall MA and Klerk G-JD (2008) The Components of Plant Tissue Culture Media II: Organic Additions, Osmotic and pH Effects, and Support System. Dordrecht: Springer, Dordrecht.

Gielis J, Gillis H, Oprins K, Oprins P and Debergh PC (2002)Tissue culture strategies for genetic improvement of bamboo. Paper presented at the 20 International Eucarpia Symposium, Melle.

Goyal AK, Pradhan S, Basistha BC and Sen A (2015) Micropropagation and assessment of genetic fidelity of Dendrocalamus strictus (Roxb.) Nees using RAPD and ISSR markers. 3 Biotech. 5(4):473-482. doi:10.1007/s13205-014-0244-7.

Islam SAMN and Rahman Md Mahbubur (2005) Micro-cloning in Commercially Important Six Bamboo Species for Mass Propagation and at a Large Scale Cultivation. Plant Tissue Cult. \& Biotech. 15(2): 103-111.

Joshi P Dhawan (2007) Assessment of genetic fidelity of micropropagated Swertia chirayita plantlets by ISSR marker assay. Biologia Plantarum.51:22-26. doi:10.1007/\$10535-007-0005-0.

Jun P (2015) Potential Medicinal Application and Toxicity Evaluation of Extracts from Bamboo Plants. J Med Plant Res. 9(23): 681-692.

Leroy XJ, Leon K, Charles G and Branchard M (2000) Cauliflower somatic embryogenesis and analysis of regenerant stability by ISSRs. Plant Cell Rep. 19:1102-1107.

Liu BH (1998)Statistical genomics: linkage, mapping and QTL analysis. CRC Press, Boca Raton,: CRC Press, Boca Raton.

Lobovikov M, Lou Yiping, Schoene Dieter and Widenoja Raya (2009)The poor man's carbon sink bamboo in climate change and poverty alleviation. INBAR,FAO, Italy: Non-Wood News Forest Products Service FAO Viale delle Terme di Caracalla.

Mandy O (2015) Bamboo Water Is Now a Thing, Health.TIME.

Mehta R, Sharma V, Sood A, Sharma M and Sharma RK (2011) Induction of somatic embryogenesis and analysis of genetic fidelity of in vitro-derived plantlets of Bambusa nutans Wall., using AFLP markers. Eur J For Res. 130(5):729-736.

Mishra Yogeshor, Patel P and Ansari SA (2011) Acclimatization and Macroproliferation of Micropropagated Plants ofBambusa tulda Roxb. Asian J. EXP. Biol. Sci. 2(3):498-501.

Mishra Yogeshor, Patel PK, Yadav Suman, Shirin Fatima and Ansari SA (2008) A micropropagation system for cloning of Bambusa tuldaRoxb. Scientia Horticulturae. 115(2008):315-318. doi:10.1016/.scienta.2007.10.002

Molnar Zoltan, Vince Emese and Ordog Vince (2011) Natural substances in tissue culture media of higher plants. Acta Biologica Szegedienis. 55(1):123-127.

Mudoi Kalpatru Dutta and Borthakur Mina (2009) In vitro micropropagation ofBambusa balcooa Roxb. through nodal explants from field-grown culms and scope for upscaling Current science. 96(7): 5.

Muniappan M and Sundararaj T (2003) Anti-inflammatory and antiulcer activities ofBambusa arundinacea. J of Ethnopharmacology. 88(2-3): 161-167. doi:https:/www.researchgate.net/ deref $/$ ttp $\% 3$ A\%2F\%2Fdx.doi.org\%2F10.1016\%2FS0378-8741(03)00183-1 
Nadha HK, Kumar R, Sharma RK, Anand M and Sood A (2011) Evaluation of clonal fidelity of in vitro raised plants of Guadua angustifolia Kunth using DNA-based markers. J Med Plants Res. 5(23): 5636-5641.

Negi D and Saxena Sanjay (2010) Ascertaining clonal fidelity of tissue culture raised plants ofBambusa balcooa Roxb. using inter simple sequence repeat markers. New Forests, 40:8. doi: 10.1007/\$11056-009-9182-3.

Negi D and Saxena Sanjay (2011) Micropropagation of Bambusa balcooa Roxb. through axillary shoot proliferation. In Vitro Cellular \& Developmental Biology - Plant volume. 47:7. doi: 10.1007/sl 1627-01 1-9403.

Oliver J (1956) Bamboo as an Economic Resource in Southern Asia. Geography. 41(1): 49-56. doi:http://www.jstor.org/stable/4056386

Pattanaik S, Das P, Borah E, Kaur H and Borah K (2004) Vegetative multiplication of Bambusa balcooa Roxb. using branch cuttings.J Bamboo Rattan. 3:365-374.

Peschke VM and Philipss R (1992) Genetic implications of somaclonal variation in plants.Adv Genet. 30:41-75.

Piper JM (1992) Bamboo and Rattan: Traditional Uses and Beliefs. Oxford: Oxford University Press.

Raina SN, Rani V, Kojima T, Ogihara Y, Singh KP and Devarumath (2001) RAPD and ISSR fingerprints as useful genetic markers for analysis of genetic diversity, varietal identification, and phylogenetic relationships in peanut (Arachis hypogaea) cultivars and wild species. Genome. 44(5): 763-772.

Ramanayake SMSD and Yakandawala K (1997) Micropropagation of the giant bamboo (Dendrocalamus giganteus Munro) from nodal explants of field grown culms. Plant Science 129(2): 213-223. doi:10.1016 \$0168-9452(97)00185-4

Re R, Pellegrini Nicoletta, Proteggente Anna, Pannala Ananth, Yang Min and Rice-Evan Catherine (1999) Antioxidant activity applying an improved ABTS radical cation decolorization assay. Free Radical Biology and Medicine. 26(9-10): 1231-1237. doi:https://doi.org/10.1016/50891-5849(98)00315-3

Risse Mark, Gaskin Julia (2013) Best Management Practices for Wood Ash as Agricultural Soil Amendment. Cooperative Extension, University of Georgia. 1(1):1-4.

Sanjaya, Rathore TS, Rai Ravishankari V (2005) Micropropagation of Pseudoxytenanthera stocksii Munro. In Vitro Cell.Dev.Biol.-Plant. 41: 333-337. doi:https://doi.org/10.1079/IVP2004625

Saxena S (1990) In vitro propagation of the bamboo (Bambusa tuldaRoxb.) through shoot proliferation. Plant Cell Rep. 9(8): 431-435. doi:10.1007/BF00232266.

Seethalakshmi KK, Venkatesh CS and Surendran T (1983) Vegetative propagation of bamboos using growth promoting substances Bambusa balcooa Roxb. Indian J For. 6:98-103.

Singh RB, Singh V, Singh KR, Toppo S, Haque N and Ebibeni N (2011) Antimicrobial effect of Artemisia vulgaris essential oil. Nat.Prod. Indian J. 5: 1-7.

Singh S, Dalal S, Singh R, Dhawan A and Kalia R (2013) Ascertaining clonal fidelity of micropropagated plants of Dendrocalamus hamiltonii Nees et Arn. ex Munro using molecular markers. In Vitro Cellular \& Developmental Biology, Plant 49(5): 572-583. doi:10.1007/\$11627013-9520-1. 
Singh SR, Dalal Sunita, Singh Rohtas, Dhawan AK and Kalia Rajwant K (2013) Evaluation of genetic fidelity of in vitro raised plants of Dendrocalamus asper (Schult. \& Schult. F.) Backer ex K. Heyne using DNA-based markers. Acta Physiol Plant. 35: 419-430. doi:10.1007/\$11738-0121084-x.

Singh SR, Dalal Sunita, Singh Rohtas, Dhawan AK and Kalia Rajwant K (2013) Limitations, progress and prospects of application of biotechnological tools in improvement of bamboo-a plant with extraordinary qualities. Physiol Mol Biol Plants. 19(10): 21-41. doi:10.1007/\$12298012-0147-1.

Stapleton C (1994) Bamboos of Nepal (Vol. 1). London: Tha Royal Botanic Garden,Kew.

Son Yong Hoon, YunJia Yan(2014) A Study on Cultural Interpretation of the Plants in "The Book of Songs" -Based on Symbolic Elements and Landscape Elements. Journal of the Korean Institute of Traditional Landscape Architecture. pp-96-109.

Sukla Rahul, Sumit G, Sajal S, Dwivedi and Ashutosh Mishra (2012) Medicinal Importance of Bamboo. International Journal of Biopharm \& Phytochemical Research. 1(1):9-15.

Suwal MM, Lamichhane J and Gauchan DP (2020) Regeneration Technique of Bamboo Species through Nodal Segments: A Review. Nepal J. Biotechnol. 8(1): 54-68. doi: https://doi.org/ 10.3126/njb.v8i1.30209

Tewari DN (1992) A Monograph on Bamboo: International Book Distributors.

Thapa N, Gauchan DP, Suwal MM, Bhuju S, Upreti A, Byanju B and Lamichhane J (2018) In Vitro Assessment of Bambusa balcooa Roxb. for Micropropagation. JETIR. 5(12): 464-469.

Upreti A, Byanju B,Bhusal A, Kuinkel S, Pokhrel B,Thapa N, Suwal MM, Lamichhane J and Gauchan DP (2016) Bambusa BalcooaRoxb. : A Novel Remedy for Peptic Ulcer.Journal of Science, Engineering, and Technology, Kathmandu University 12(2): 88-95. doi:10.3126/ kuset.v12i2.21525

Van der Lugt P, Thanglong T and King C (2018) Carbon Sequestration and Carbon Emissions Reduction Through Bamboo Forests and Products. Retrieved from INBAR: https://www. inbar.int/resources/inbar_publications

Venkatachalam L, Shreedhar RV and Bhaghyalakshmi N (2007) Micropropagation in bananas using high levels of cytokinins does not involve any genetic changes as revealed by RAPD and ISSR markers. Plant Growth Regul.51:193-205.

Vishwanath S, Joshi G, Somashekhar P, Rane A, Sowmya C and Joshi S (2012) Dendrocalamus stocksii (Munro): A potential multipurpose bamboo species for peninsular India. A Publication of Institute of Wood Science \& Technology, Bangalore, IWST Technical Bulletin No. 10: 10.

Wróblewska Katarzyna B, Oliveira Danielle CS de, Grombone-Guaratini Maria Tereza and Moreno Paulo Roberto H (2019) Medicinal Properties of Bamboos. Pharmacognosy Medicinal Plants.

Zietkiewiez E, Rafalski A and Labuda D (1994) Genome Fingerprinting by simple sequence repeat (SSR)-anchored polymerase chain reaction amplification. Genomics 20: 176-183. 